\title{
Cultural and linguistic testing of the Handling Questionnaire: a specific instrument for assessing the patient's acceptability of dry powder inhalers
}

\author{
R.W. Dal Negro1, M. Guerriero2
}

\begin{abstract}
Cultural and linguistic testing of the Handling Questionnaire: a specific instrument for assessing the patient's acceptability of dry powder inhalers. R.W. Dal Negro, M. Guerriero.

The testing and checking phases of a questionnaire are briefly described in this paper, identifying the common errors due to incorrect formulation of questions and the
\end{abstract}

main issues. The theoretical methods for "testing" a questionnaire has been examined in the first section, in the second section the testing process for a specific questionnaire for assessing the patient's acceptability of a dry powder device (the Handling Questionnaire) has been described, together with the grading of improvement achieved. Monaldi Arch Chest Dis 2008; 69: 4, 170-177.

Keywords: Questionnaire, Testing, Pre-test, Reliability, Validity, Question, Response, Dry powder device, Handling Questionnaire.

1 Lung Dept., Orlandi Hospital, Bussolengo, Verona;

2 E.S.I. Department, Statistics Section, University of Verona, Via Dell' Artigliere, 19 - 37129 Verona, Italy.

Correspondence: M. Guerriero, E.S.I. Department, Statistics Section, University of Verona, Via Dell'Artigliere, 19 - 37129 Verona, Italy.

\section{Introduction}

Questionnaires are the most commonly used instrument for investigational research designed to collect data and information on a given topic. By using a questionnaire it is possible to obtain significant and low-cost information concerning a specific group of individuals in short time. However, in order to achieve the expected results, those who use a questionnaire should be able to rely on a valid and reliable instrument, suitable for ensuring the effective completion of data collection [1-5].

In addition, the subsequent procedure used for checking the effectiveness of a given questionnaire (the so-called "testing phase") is equally crucial. A number of systematic mistakes (partially or wholly incomplete answers, random answers, false answers etc.) are often made which can, as a result, induce incorrect answers during the subject's interview which can adversely affect the original researcher's version of the questionnaire [6-9].

The present paper will describe the essential traits of both the testing and translation phases of a questionnaire from a methodological point of view. Subsequently, these procedures will be applied to a specific questionnaire aimed at investigating patients' preferences between two different devices for inhaling anti-asthma drugs: the "Handling Questionnaire".

\section{Materials and Methods}

In order to better perceive the different procedural steps of validation, the Handling Question- naire is reported in the original version (Appen$\operatorname{dix} 1)$.

In Appendices 2 and 3 are reported together both the final Italian and English validated versions which have been obtained following the validation procedures.

\section{Results and Validation steps}

The original Italian version of the questionnaire "Dry powder inhalers. Questionnaire on device acceptability 2" (Appendix 1) was submitted to a sample of 22 individuals (the typical sample size for a pilot survey) without any knowledge on respirology.

Their gender; age, and level of education are reported in tab. 1.

As mentioned above, the aim was to detect any possible structural defects in the questionnaire, or the existence of peculiar systematic errors which should be highlighted during the interviews.

It should be noted that the Handling Questionnaire drawn up by the researcher did not present any structural problem and it was in line with the objectives of the survey. Nevertheless, some mistakes became evident during the pre-test and some changes and corrections were necessary.

First, some English terms had to be replaced in the Italian version, namely the term "nurse" (which was present in both questions 1.2.1 and 3) was regarded as too difficult to understand. There is no doubt that at present this term is widely and commonly used also in Italian, but considering the heterogeneous nature of the testing sample, it could not in any way be presumed that this term 


\begin{tabular}{|c|c|c|c|c|c|c|}
\hline & & \multicolumn{4}{|c|}{ Sex } & \multirow{4}{*}{$\begin{array}{c}\text { Total } \\
8\end{array}$} \\
\hline & & \multicolumn{2}{|c|}{ Male } & \multicolumn{2}{|c|}{ Female } & \\
\hline \multicolumn{2}{|c|}{$\begin{array}{c}\text { Academic } \\
\text { qualification }\end{array}$} & $\begin{array}{c}\text { High school diploma } \\
\text { or degree }\end{array}$ & $\begin{array}{c}\text { Junior or middle } \\
\text { school }\end{array}$ & $\begin{array}{l}\text { High school diploma } \\
\text { or degree }\end{array}$ & $\begin{array}{c}\text { Junior or middle } \\
\text { school }\end{array}$ & \\
\hline \multirow[t]{3}{*}{ Age } & $<19$ & 2 & 2 & 2 & 2 & \\
\hline & $19-60$ & 2 & 2 & 2 & 2 & 8 \\
\hline & $>60$ & 1 & 2 & 1 & 2 & 6 \\
\hline \multicolumn{2}{|c|}{ Total } & 5 & 6 & 5 & 6 & 22 \\
\hline
\end{tabular}

would be understood easily and effectively by all subjects (the elder subjects and/or those with the lower cultural levels). This was also the case for the term "device", which was repeated several times in the original Italian version of the questionnaire (title included). It was then suggested that these two terms be replaced with their Italian equivalents, namely "infermiere/a" and "dispositivo", respectively.

One individual had some difficulties in understanding the term "inhaler" which was included in question 1. However, as this subject was not a respiratory patient (asthmatic), the word was not replaced in this case.

Furthermore, question number 3 of the original version (see appendix 1) had two lines following the word "why" where the interviewee was invited to list the reasons why one inhaler was, in his opinion, simpler to use than the other. These two lines were preceded by the letters A and B respectively, in order to identify the two devices:

Why?

A

$B$

In order to ensure the full and more effective comprehension of the text it was suggested that a single line of space without any identifying letter was inserted, because the preference for one of the two devices has already been expressed in the previous question. The question was then rewritten in the following version:

Which one seems easier to use? $A$ Why?

This new formulation tends to minimise the possibility that the interviewee may attribute the opposite meaning to his own response.
The question that caused most problems vis- $a$ vis comprehension was number 5, being the misunderstanding due to the different interpretation of the term "preparation". In fact, the interviewed individuals did not know whether the true sense of the word of "learning" (such as, after how many attempts did the subject feel sufficiently "prepared" to use the device correctly), or of "assembly/ mounting" (such as, after how many attempts did the subject manage to correctly assemble both the inhalers in order to use them). The ambiguous interpretation of this term was likely due to the terms "attempts/demonstration" reported in the same question, which were considered as synonyms by the researcher. Question number 5 was then rewritten accordingly to the following version:

\section{(specific question directed only to the Nurse)}

Please indicate the $n$. of attempts the patient needed to correctly actuate inhalation for each DPI.

$$
A
$$

The percentage of comprehension for each question at the first reading of the questionnaire are reported hereafter:

1. Have you had any previous experience with dry powder inhalers? YES/NO

(22/22 - 100\%)

2. You have two different DPI devices in front of you: which one most arouses your curiosity? A/B (22/22 - 100\%)

3. Which one seems easier to use? (after the demonstration by the nurse) (A/B)

Why? A

$\mathrm{B}$

$(12 / 22-55 \%)$ 
4. What seems the most critical point in their practical use? (after having experienced both the devices)

$$
\text { A }
$$

$$
\text { (21/22-95\%) }
$$

5. After how many attempts/demonstrations was correct preparation achieved?

A B

(10/22 - 45\%)

6. In your opinion, which device seems the best in terms of:

1. Shape of the device

$$
\text { (22/22 - 100\%) }
$$

2. Ease of grip

$$
\text { (22/22 - 100\%) }
$$

3. Weight

$$
\text { (22/22 - 100\%) }
$$

4. Height

$$
\text { (22/22 - 100\%) }
$$

5. Hygiene

$$
\text { (18/22 - 82\%) }
$$

6. Awareness of residual doses

$$
\text { (22/22 - 100\%) }
$$

7. Ease of learning how to use it

$$
\text { (22/22 - 100\%) }
$$

8. Ease of use

$$
\text { (22/22 - 100\%) }
$$

9. Number of manoeuvres necessary for use (22/22 - 100\%)

10. Coordination

$$
\text { (15/22 - 68\%) }
$$

11. Ease of use in critical conditions

$$
\text { (22/22 - 100\%) }
$$

I will now ask you about a specific inhaler:

7. If you use any powder inhalers, have you ever used the Turbohaler device? YES/NO

\section{(22/22 - 100\%)}

7.1 If YES, were you provided with any instructions on its use: YES/NO

$$
\text { (22/22 - 100\%) }
$$

7.2 If YES, by whom?

$$
\text { (22/22 - 100\%) }
$$

the Specialist $\square \quad$ the GP $\square \quad$ the Nurse $\square$ Relatives $\quad \square \quad$ Friends $\square$ Other

8. And to finish, the last question.

How old are you?

$$
\text { (22/22 - 100\%) }
$$

(upon observation of the interviewer)

Sex $\quad M / F \quad(22 / 22-100 \%)$
Other minor changes were made to the original version of the questionnaire.

The items concerning both the age and sex of the interviewee were shifted to the final section of the questionnaire. As they deal with personal details, this kind of questions might be perceived by the interviewees as an intrusion of their privacy [1-3]. Consequently, it is probable that those who refused to answer these questions also decided to interrupt the interview. Once these questions are switched to the end of the questionnaire, the content of the interview will be much more preserved.

The questions specifically regarding the use of the Turbohaler device (questions n. 1.1, 1.2, 1.2.1 in the original version) were also moved to the end of the questionnaire. Some individuals involved in the pre-test phase pointed out that one of the two inhalers provided for the comparison was precisely the one mentioned above. It was therefore presumable that the subjects who were still using the Turbohaler (or who had used it at least once in the past) had already had a structured opinion on that (regardless of whether it was positive or negative), and their answers in this case could result significantly affected by their own previous experience.

A much more appropriate numbering system was also introduced for these questions, in order to clarify to the interviewee that this battery of questions was dependent of the main previous question.

The items comparing the two devices (questions n. 6-16 in the original version) were reordered according to different criteria which would better contribute to the interviewee's opinion concerning the characteristics of the two inhalers. Also in this section the numbering was changed.

A short introduction describing the general functioning of the dry powder inhalers was added at the beginning of the questionnaire. We cannot in fact rule out that some patients who will participate in the survey are not provided with sufficient knowledge on the devices they have to experience and comment.

It is a good practice indeed to make the interviewees aware that their contribution is extremely important to the research. Just in order to emphasise the value of this approach, a short thanking sentence was included at the end of the questionnaire: it will contribute to reinforce the interviewer/interviewee relationship, and increase the probability that the same subject will agree to participate in future studies.

Finally, the graphical format of the questionnaire was also revised (fonts, layout, colours).

The English version of the tested questionnaire was realised using the technique of translation and back-translation with the contribution of professionals of this particular discipline of human science. The English translation of the original researcher's version of the Handling Questionnaire and both the validated version in Italian and in English are reported in the Appendices 2 and 3 . 


\section{Discussion}

There is widespread consensus in the literature on the evidence that the pre-test procedure represents the true crucial phase for developing a new questionnaire: actually, this is the last phase for refining the operational instrument which was created for carrying out the survey and it would then be effective enough in terms of its whole structure as well as of the language used.

Usually, the researcher aims to assess the real effectiveness of this instrument during the pre-test phase by administering it to a limited number of subjects [6] The sample of individuals involved does not need necessarily to represent a cluster of the true population to investigate during the real survey.

According to Bailey [3] the individuals used for checking the accuracy of the questionnaire may be chosen among the researcher's colleagues, or one's own friends, or family members and relatives, etc.: in other words, people who are easily and quickly available for this purpose. In order to avoid any misunderstanding, it should be highlighted that the requisites of "relevance" (i.e. a direct or indirect connection between the questions contained into the questionnaire and the individuals to interview) should not be ignored. Bailey himself warns that "there will not be used males alone for the pre-test of a questionnaire regarding pregnancy, unless there is absolutely no choice". It is nevertheless advisable to include subjects of both sexes, of all age groups, and with different cultural levels in the pre-test sample.

The methodology for the pre-test phase should coincide with that of the final survey [10-11]. In the case of direct or telephone interviews, also the pre-test should thus be performed by oral interviews. On the contrary, when dealing with questionnaires to be filled directly by the interviewees, it is advisable to use self administered instruments also in the pre-test phase. In any case, Bailey [3] and Marvulli [4] advised to inform interviewees that they are taking part in a pre-test procedure, and not in the real survey.

The interviewer who conducts the pre-test should provide incentives for the subjects asked to perform a critical analysis of the questionnaire. Part of the mistakes occurring when preparing and drawing up a new questionnaire are identified only thanks to the contribution of potential respondents, and it would therefore represent a good idea to examine in this phase all their comments, doubts and requests for clarifications when they are facing the list of questions for the first time. In this phase, the relationship existing between the two subjects involved (namely, the interviewer and the interviewee) is thus less formal than during the proper survey, such as when the respondent is invited to stick to the point and to avoid any digression [12-14].

Particular attention should be given to the structure of the questions; to their order in the list; to the presence of embarrassing questions or words typical of particular groups of subjects which may be difficult to understand for other groups of subjects; to the use of terms which may appear offensive for certain individuals; to useless, or not relevant, or redundant questions, as well as to the average duration of the interview [12].

Each questionnaire (with all questions included) should be checked in terms of its validity and reliability. The former identifies the instrument's ability to measure effectively one aspect with an accepted degree of precision. The latter consists in its ability to provide stable measurements of the same aspect in similar conditions over time [6].

If the questionnaire mainly contains closed questions with some pre-defined options of response (the so-called "structured questionnaires"), the pre-test phase can contribute to identify possible missing options: the presence of an incomplete list of preferences is extremely dangerous, since some respondents who do not find their preferred option in the list may abandon the interview because irritated. All these comments should be noted by the interviewer during the pre-test phase, and reported to the researcher because of a great value [5].

Another relevant goal of the testing process consists in the identification and the subsequent elimination of the "set responses phenomena", namely the systematic choice of the same interviewee's answer regardless of the question asked. This condition usually occurs when several "batteries" of questions are associated with the same list of possible options (e.g.: very much; fairly; not very much; not at all) in the questionnaire. However, it should be emphasised that the systematic use of the same option does not necessarily depend exclusively on the superficial approach of the respondent. Sometimes it due to insufficient alternatives in the list of answers: in these cases, the interviewee is obliged to choose the option which is the "closest" to his vision [6].

The identification of "unclear" or "ambiguous" questions is certainly one of the main goals of the pre-test procedure. The use of a language simple and clear enough to allow the complete comprehension to all categories of individuals is a crucial point. Any question which proves difficult to understand or of doubtful interpretation during the pre-test phase should be reviewed and reformulated [7].

However, it is important to pinpoint that possible problems can be recognised not only through the answers which are solicited by the questions (e.g.: "I don't know" or "I refuse to answer the question"), but also by other signals which can be caught by the interviewer at the moment of asking them: these situations should be described and noted carefully by the interviewer [5].

As conventional pre-test methods do not prevent and cover all possible difficulties of respondents, namely hesitation or unease in answering [7], a greater awareness of these potential limitations of conventional pre-testing has led to the development of other methods in recent decades, such as: cognitive interviews; behaviour coding; 
response latency and vignette analysis. While aware of this, the relatively simple nature of the Handling Questionnaire and the limited duration of the interview led us to regard the conventional pre-test phase as adequate and sufficient enough for developing the reference questionnaire.

Finally, it is worth making a few comments on the translation of the questionnaire from the "research" language to another. In many cases the same interview has to be carried out on individuals of different cultures, different nationalities and, consequently, different languages. This leads to the need to translate the questionnaire into a different language from that spoken by the researcher (called, in fact, the "research language"), even though the "correctness" of such an operation is still debated [8].

Actually, while being convinced that the text needs to be translated into other languages, some Authors are wondering whether it is a good idea to use the term "translation". intended as a mere rewriting of a test into a different language without making any change. A great proportion of the effectiveness of these instruments depends on formulation of the questions they contain. In other words, the use of one word in place of another, or its positioning in a specific point of the sentence, is not a researcher's "whim" but a decision directly linked to a precise meaning. Therefore, in order to construct a true effective instrument, it is necessary to consider the two questionnaires (that one in the research language and the other in the foreign language) as they were two distinct instruments with a common objective, and not as the same instrument written in two different languages [15-17].

One of the most widely used methods used for translating a questionnaire from one language to another is the "translating/back-translating method", which consists of four different operational phases [15-16]:

- initial translation from the research language to the foreign language by a bilingual translator;

- back-translation: in other words, a new translation, this time from the foreign language to the research language by a translator different from that one who performed the first translation, and who is not familiar with the original version of the questionnaire;

- comparison between the two versions of the questionnaire written in the research language; - in the event of substantial differences between the two versions, preparation of a new draft translation containing the necessary changes is needed.

In conclusion, a questionnaire represents a widespread, cheap, helpful, and sometimes specific instrument for investigational research concerning people's behaviours and beliefs.

Of the several factors which can affect results of this kind of research, the validity of the questionnaire in terms of full comprehension of all questions included, and of repetition of the interviewee's responses still represent topic issues.

The procedure to actuate for checking the reliability and the effectiveness of a given questionnaire (such as, the so-called "testing phase") is essential in the validation process because it leads to the identification and the elimination of the those mistakes which could otherwise heavily bias the final results of the survey.

Actually, a careful testing phase should be regarded as a mandatory phase oriented to minimize the effects of both the insufficient comprehension or of the incorrect formulation of all questions which constitute the questionnaire itself.

Only once checked from this point of view, the questionnaire, as in the case of the Handling Questionnaire, can be extensively used for its original purposes.

\section{References}

1. Phillips BS. Social Research: Strategy and Tactics, second edition, New York, Macmillan, 1971.

2. Phillips BS. Social Research: Strategy and Tactics, third edition, New York, Macmillan, 1976.

3. Bailey KD. Methods in social Research, 1978; Italian trans. Metodi della ricerca sociale, Bologna, Il Mulino, 1985.

4. Marvulli R. I questionari, Torino, Giappichelli, 1985.

5. Kahn RL, Cannell CF. Interviewing: social research, in International Encyclopedia of the Social Sciences, 1968, VIII.

6. Converse JM, Presser S. Survey questions. Handcrafting the standardized questionnaire, Beverly Hills, Ca., Sage, 1986.

7. Presser S, et al. Methods for Testing and Evaluating Survey Questionnaires, New York: Wiley-Interscience, 2004.

8. Behling O, Law KS. Translating Questionnaires and Other Research Instruments: Problems and Solutions, SAGE University Paper, 2000.

9. Churchill GA. Marketing Research: Methodological Foundations, The Dryden Press, New York, NY, 1995.

10. Groves R, et al. Survey Methodology, New York: Wiley-Interscience, 2004.

11. Manganelli Rattazzi AM. Il questionario: aspetti teorici e pratici, Cleup editrice Padova, 1990.

12. Saw SM, Ng TP. The Design and Assessment of Questionnaires in Clinical Research. Singapore Med J 2001.

13. Selltiz, et al. Research Methods in Social Relations, third edition, New York, Holt, Rinehart, and Winston, 1976.

14. Siegel PM, Hodge RW. A Causal Approach to the Study of Measurement Error, in Methodology in Social Research, edited by Blalock HM Jr and Blalock AB, New York, McGraw-Hill, 1968.

15. Geisinger KF. Cross cultural normative assessment: Translation and adaptation issues influencing the normative interpretation of assessments. Psychological Assessment 1994; 6: 304-12.

16. Harkness J, Pennel B, Schoua-Glusberg A. Survey Questionnaire Translation and Assessment, in Method for Testing and Evaluating Survey Questionnaires, ed. Presser et al, New York: Wiley-Interscience, 2004.

17. Stahl E, Postma D, Juniper E., Svensson K, Mear I, Lofdahl C. Health-related quality of life in asthma studies. Can we combine data from different countries? Pulmon Pharmacol Therapeut 2003; 16: 53-59. 


\section{Appendix 1. - The original version of the "DRY POWDER INHALERS QUESTIONNAIRE” before validation}

\section{DRY POWDER INHALERS \\ QUESTIONNAIRE ON DEVICE ACCEPTABILITY 2}

Age.

Sex $\quad M \quad F$

1. Have you had any previous experience with dry powder inhalers:

1.1 If YES, have you ever used the Turbohaler device?:

YES NO

1.2 If YES, where you provided with any instructions on its use?:
1.2.1 If YES, by whom? the Specialist $\square \quad$ the GP $\square \quad$ the Nurse $\square$ Relatives $\quad \square \quad$ Friends $\square \quad$ other

You have two different DPI devices in front of you:

2. Which one most arouses your curiosity?

3. Which one seems easier to use? (after the demonstration of the nurse)

Why?

A

$\boldsymbol{B}$

4. What seems the most critical point in their practical use? (after having experienced both the devices) A $\boldsymbol{B}$

5. After how many attempts/demonstrations was correct preparation achieved?

In your opinion, which device seems the best in terms of:

6. Awareness of residual doses

7. Hygiene

8. Shape of the device

9. Ease of use

10. Number of manoeuvres necessary for use

11. Ease of grip

12. Coordination

13. Weight

14. Height

15. Ease of learning how to use it 


\section{Appendix 2. The Italian validated version of the Handling Questionnaire}

\section{POLVERI SECCHE INALATORIE QUESTIONARIO DI ACCETTABILITÀ - 2}

Alcuni medicinali per l'asma possono essere assunti sotto forma di polveri secche inalatorie utilizzando un piccolo strumento manuale chiamato inalatore di polveri secche o "DPI." Ogni singolo inalatore di polveri secche ha un modo specifico di caricare e inalare le dosi. Il vantaggio nell'utilizzo degli inalatori di polveri secche e' che sono attivati dal respiro. In questo modo la somministrazione della medicina è sempre coordinata con l'inalazione.

La sua opinione è di valore e aiuterà a sviluppare migliori inalatori di polveri secche. Il suo aiuto è molto apprezzato.

1. Ha precedente esperienza nell'uso di polveri inalatorie?

Ha di fronte a sé due differenti inalatori di polveri:

2. Quale la incuriosisce di più?

A B

3. Quale le sembra più facile da utilizzare? (dopo la dimostrazione dell'infermiera)

Perché?

4. Quale le sembra il punto più critico nel loro utilizzo pratico? (dopo aver provato entrambe i dispositivi) A

B

5. (domanda specifica a compilazione dell'infermiera)

Indichi il numero di tentativi necessari al paziente, per ogni dispositivo, per effettuare correttamente l'inalazione
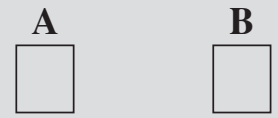

6. Secondo la sua opinione, quale dispositivo le sembra migliore riguardo a:

1. Forma del dispositivo

A B

2. Facilità d'impugnatura

A B

3. Peso

4. Altezza

A B

5. Igiene

A B

6. Conoscenza del numero di dosi rimaste

A B

7. Facilità d'apprendimento

A B

8. Facilità d'uso

9. Numero di manovre necessarie per l'utilizzo

10. Coordinamento

11. Facilità di utilizzo in condizioni critiche

Ora le farò una domanda riguardo ad uno specifico inalatore:

7. Se utilizza polveri inalatorie, ha avuto modo di utilizzare il dispositivo Turbohaler?:

7.1 Se SI, ha ricevuto istruzioni sul suo utilizzo:

\subsubsection{Se SI, da chi? Medico specialista $\square \quad$ Medico Generico $\square \quad$ Infermiera Parenti \\ Amici \\ Altro}

E per finire ecco l'ultima domanda. Quanti anni ha?

(per osservazione dell'intervistatore)

Sesso M F

Grazie molte. La sua opinione è molto importante per noi! 


\section{Appendix 3. The English validated version of the Handling Questionnaire}

\section{DRY POWDER INHALERS (DPI) \\ QUESTIONNAIRE ON DEVICE ACCEPTABILITY \\ The Handling Questionnaire}

Some asthma medications can be taken in the form of a dry powder using a small, hand-held device called a dry powder inhaler, or "DPI." Each of the dry powder inhalers involves a specific way of loading and inhaling the dose. The advantage of using a dry powder inhaler is that it is breath-activated. In this way, the breath-activated discharge of medicine is always coordinated with inhalation effort.

Your opinion is very valuable and will help us to develop improved Dry Powder Inhalers. Your help is very much appreciated.

1. Have you had any previous experience with dry powder inhalers?:

Yes No

\section{You have two different DPI devices in front of you:}

2. Which one most arouses your curiosity? (to be answered after the Nurse's demonstration) A B

3. Which one seemed easier to use? $\quad$ A B

Why?

(to be answered after trying out both devices)

4. What criticisms do you have of each device:

A

B

5. (specific question directed only to the Nurse)

Please indicate the no. of attempts the patient needed to correctly actuate inhalation for each DPI

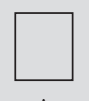

A

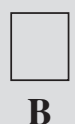

6. In your opinion, which device offers the most convenience in terms of:

1. Shape

2. Ease of grip

3. Weight

4. Height

5. Hygiene

6. Awareness of residual doses

7. Ease of learning how to use it

8. Ease of use

9. N. manoeuvres needed to activate the DPI

10. Degree of coordination needed to activate the DP

11. Ease of use in critical conditions

Now, I want to ask you a question about a specific inhaler:

7. Have you ever used the Turbuhaler?

7.1 Were you provided with any instructions for its use?

7.1.1 If YES, from whom did you receive instructions?

$\begin{array}{lll}\text { The Specialist } \square & \text { the GP } \square & \text { the Nurse } \square \\ \text { Relatives } \quad \square & \text { friends } \square & \text { others } \square\end{array}$

The last question. How old are you? Age .

(Upon observation of the nurse)

Sex M F

THANK YOU. Your opinion is very valuable to us! 